\title{
Nanostructured ZnO and ZnO: Pd with MXene overlayer SPR biosensors
}

\author{
V. R. Sudheer ${ }^{1,2} \cdot$ S. R. SarathKumar ${ }^{3} \cdot$ S. Sankararaman ${ }^{1}$ (D) \\ Received: 2 September 2020 / Accepted: 8 June 2021 / Published online: 24 June 2021 \\ (C) The Author(s), under exclusive licence to Springer Science+Business Media, LLC, part of Springer Nature 2021
}

\begin{abstract}
The development of biosensors based on various novel techniques has become highly significant in the context of the outburst of a pandemic like COVID 19. The present work reports the theoretical modeling of two surface plasmon resonance (SPR) based biosensing probe configurations on optical fiber employing Metal/ZnO/MXene and Metal/ZnO: $\mathrm{Pd} /$ MXene. Maximum sensitivities of 19,400 nm/RIU and $8350 \mathrm{~nm} / \mathrm{RIU}$ are calculated with Metal/ZnO/MXene and Metal/ZnO: Pd/MXene, respectively. The sensors are suitable for analytes with refractive index values ranging from 1.354 to 1.422 . The refractive index of mucus and serum being in this range, the proposed biosensor, can be a potential tool for COVID-19 detection.
\end{abstract}

Keywords MXene $\cdot$ SPR $\cdot$ Hybrid nanostructure $\cdot$ Biosensor

\section{Introduction}

Today we are at a crucial junction where the entire world is being shocked by the fatal epidemic of Corona Virus disease (COVID-19). The corona virus belongs to the viruses that may cause the common cold, influenza-like illnesses, nephritis, respiratory illnesses like pneumonia and bronchitis. Middle East Respiratory Symptom (MERS), Severe Acute Respiratory Symptom (SARS), and the COVID-19 are some of the severe symptoms caused by the corona virus family (Huang et al. 2009). Despite all the acquired medical and technological achievements, the epidemic is spreading at lightning speed, raising the death toll to around two lakhs. Hence early, accurate, and fast detection of the human corona virus

S. R. SarathKumar

sarath.sr.nair@gmail.com

S. Sankararaman

drssraman@gmail.com

1 Department of Optoelectronics, University of Kerala, Karyavattom, Thiruvananthapuram 695581, India

2 Department of Electronics and Communication, College of Engineering, Perumon, Kollam 691601, India

3 Department of Nanoscience and Nanotechnology, University of Kerala, Karyavattom, Thiruvananthapuram 695581, India 
is essential. Studies confirm that the corona virus gets transmitted through body fluids and social contacts. The endogenous biochemical processes within the human body and the defense mechanism of the tissues against intruders like virus results in the formation of many volatile organic compounds (VOC) as by-products and reflect in the body fluids and the exhaled gases. The constituents in the exhaled air and the body fluids can throw light into the health condition of human beings (Galassetti et al. 2005; Ruzsányi and Péter Kalapos 2017). It can provide diagnostic information on the early detection of various diseases. Many types of biosensors have been developed so far. The biosensors have become a potential tool in the early detection of diabetes (Gruber et al. 2016), abnormalities with lungs (Nardi-Agmon and Peled 2017) and blood serum (Liu et al. 2019).

A wide variety of sensors working on different technologies and materials are available. The quality of sensors has been improved much with hybrid nanostructures (Andre et al. 2018). For accurate and quick sensing, the sensors should have better adsorption to various functional groups, quick response characteristics, and chemical stability. Recently, MXenes have revolutionized the sensing arena (Sinha et al. 2018; Zhu et al. 2017). Among the various optical sensors based on different techniques, such as infrared spectroscopy ( $\mathrm{Li}$ et al. 1990), ultraviolet-visible spectroscopy (Tredgold et al. 1985), ellipsometry (Beck et al. 2011), and surface plasmon resonance (SPR) (Tabassum and Gupta 2015a,b), the SPR sensors stand apart as a better choice. The sensors based on the principle of SPR have proved to yield quick and accurate sensing of physical, chemical, and biochemical parameters (Sharma and Gupta 2007; Jorgenson and Yee 1993; Ghosh et al. 2013). SPR sensors make use of the Kretschmann configuration (Homola 1997). When a metal is placed in contact with a dielectric and is excited by an optical signal, resonant oscillation called surface plasmons, of the free electrons at the interface between a metal and a dielectric may happen when the wave vectors of the conducting electron cloud and evanescent waves match. SPR sensors operate on the above principle. Surface plasmons are exponentially decaying transverse magnetic (TM) polarized non-radiative electromagnetic signals propagating parallel to the metal-dielectric interface. The principal advantageous feature of SPR is that, even minor variations of refractive index (RI) in the boundary of the metal and dielectric will largely influence the resonance conditions of the surface plasmons.

Adsorption of external materials to the surface alter the refractive index, and hence SPR based sensors ensure efficient sensing applications. For harnessing the advantages of optical fibers, the Kretschmann configuration is modeled to be implemented with optical fibers and are called fiber optic SPR sensors (Villuendas and Pelayo 1990). When white light is focused on one end of the fiber optic sensor, maximum energy from the transmitted light gets transferred at resonance to the surface plasmons. Hence, a corresponding dip appears at the recorded output waveform at the other end of the fiber. This waveform is the SPR curve. The resonant wavelength $\left(\lambda_{\text {res }}\right)$ changes with change in the RI of the sensing medium, and hence calibration of the wavelength shift for a specific change in RI can yield the sensitivity. These fiber optic SPR sensors enable compactness, ease of sensing, high sensitivity, fast sensing, and reliability for noninvasive measurements in sensing and biosensing.

In the proposed theoretical modeling, fiber optic SPR hybrid nanostructured sensing probes with aluminium ( $\mathrm{Al}$ ), zinc oxide $(\mathrm{ZnO})$, Palladium (Pd), and $\mathrm{Ti}_{3} \mathrm{C}_{2} \mathrm{~T}_{\mathrm{x}}$ MXene, suitable for biomedical applications is considered. MXenes are two dimensional materials derived from the $M_{n+1} A X_{n}(M A X)$ phases, where $M$ is an early transition metal, $A$ is a group 13 or 14 element, and $\mathrm{X}$ is carbon or a combination of carbon and nitrogen. They possess high hydrophilicity, large surface area, and are easy to functionalize. The unique physical, chemical, and ion transport properties make them a prominent choice in many 
applications, especially sensing and biosensing (Sinha et al. 2018; Zhu et al. 2017; Wu et al. 2018). MXenes feature excellent biocompatibility and allow secure immobilization of enzymes and proteins on its surface (Wu et al. 2018; Rakhi et al. 2016; Wang et al. 2015a). They possess a large specific surface area and anisotropic conductivity of charge carriers, together with environmental friendliness and excellent chemical stability (Sinha et al. 2018; Zhu et al. 2017). The presence of surface dangling bonds enables MXenes to attract various functional groups, which make them a unique choice for sensing applications (Sinha et al. 2018; Zhu et al. 2017; Wang et al. 2015b; Sudheer et al. 2020).

$\mathrm{ZnO}$ is an II-VI compound semiconductor with a direct and large bandgap. The ionicity resides at the borderline between covalent and ionic semiconductors. $\mathrm{ZnO}$ has high thermal and chemical stability, substantial mechanical strength, sizeable piezoelectric coefficient, high exciton binding energy, and optical gain, making it an ideal material to realize excitonic devices at room temperature (Tabassum and Gupta 2015a, b; Özgür et al. 2005; Shukla et al. 2015). Palladium is an attractive metal that has been used as a stable Schottky contact of wide bandgap and is a good conductor with superior thermal and chemical stabilities (Tabassum and Gupta 2015a, b; Abd Rahim et al. 2011). Pd nanoparticles possess excellent SPR features, which could lead to applications in colorimetric sensing, plasmonic waveguiding, enhancement of electromagnetic fields and light transmission, and optical sensing of hydrogen (Hamed 2016). Pd is very resistant to oxidation and corrosion and possesses excellent catalytic properties. It is also chemically stable.

Reverse transcription-polymerase chain reaction (RT-PCR), serological testing, and antibody-based testing were earlier used to detect the coronavirus. Detection based on antigens like N-protein also yielded better results as these proteins can be detected even early as on the first day of infection. Different methods like enzyme-linked immunosorbent assay (ELISA), immunofluorescence assay, and enzyme-linked immunosorbent assay using chemiluminescence (CLEIA) were utilized for detecting N-proteins (Huang et al. 2009). Literature shows that studies were also conducted on the refractive index (RI) of the coronavirus (Hamed 2016; Pang et al. 2016). All of the above test procedures are timeconsuming. The proposed fiber-optic SPR sensor has the advantage of the compact size and flexibility of the optical fiber combined with the unique properties of the outer layer of MXene. Hence the sensor can facilitate simple, fast, and accurate invasive and noninvasive sensing of body fluids. We strongly believe that our proposed sensing probe structures can guide the development of sensors for fast and accurate detection of coronavirus infection.

\section{Experimental considerations and theoretical modeling}

Many sensor configurations have already been proposed with $\mathrm{ZnO}$ and nanocomposite of $\mathrm{ZnO}$ and $\mathrm{Pd}$ with enhanced sensitivity. For harnessing the features and properties of $\mathrm{ZnO}, \mathrm{Pd}$, and $\mathrm{MXene}$, two different hybrid nanostructure sensor configurations are proposed-Metal/ZnO/ $\mathrm{Ti}_{3} \mathrm{C}_{2} \mathrm{~T}_{\mathrm{x}}$ and Metal/ZnO: $\mathrm{Pd} / \mathrm{Ti}_{3} \mathrm{C}_{2} \mathrm{~T}_{\mathrm{x}}$. Simulations are done with aluminium as the metal and $\mathrm{Ti}_{3} \mathrm{C}_{2} \mathrm{~T}_{\mathrm{x}}$ as the outer layer interacting with the analyte. Here we propose to remove the cladding for a length of $1.5 \mathrm{~cm}$ from a Plastic Clad Silica (PCS) fiber of core diameter $600 \mu \mathrm{m}$ and numerical aperture of 0.24 . This cladding removed portion is coated with the thin film of aluminium. The proposed sensing probe is illustrated in Fig. 1. In the first configuration, a thin layer of $\mathrm{ZnO}$ is sandwiched between the metal and $\mathrm{Ti}_{3} \mathrm{C}_{2} \mathrm{~T}_{\mathrm{x}}$ layers, whereas in the second configuration, the $\mathrm{ZnO}$ layer is replaced with a nanocomposite of $\mathrm{ZnO}$ and Palladium. A beam of collimated 


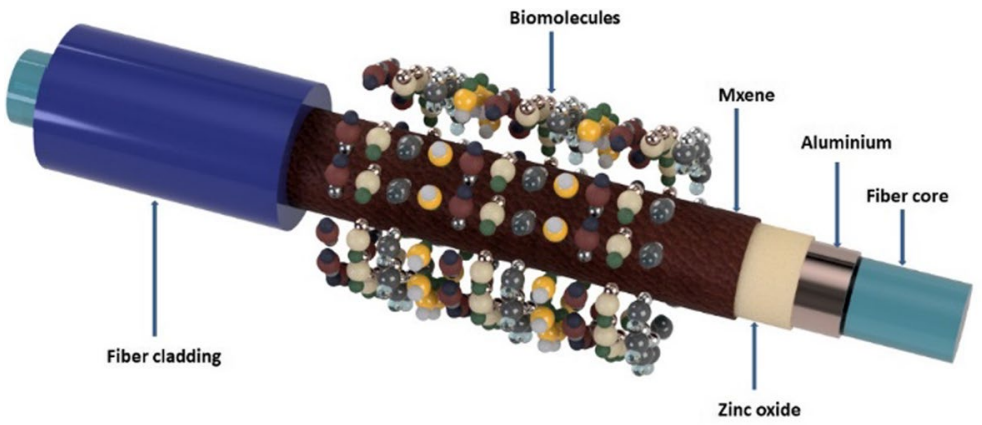

(a)

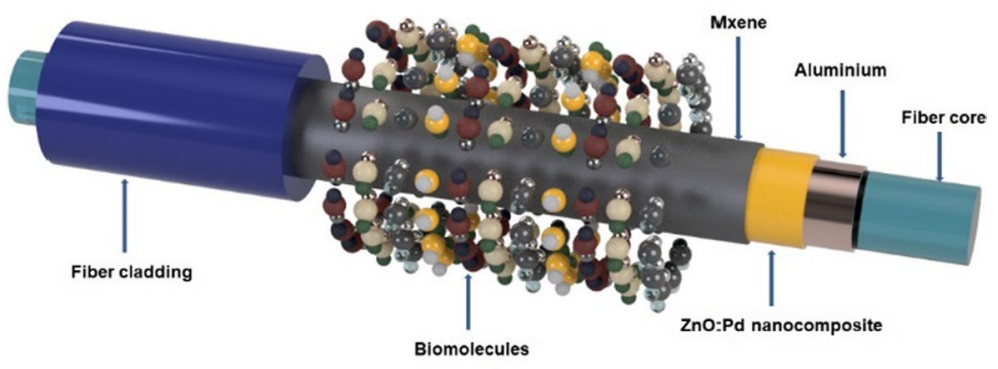

(b)

Fig. 1 Schematic of the proposed sensing probes $\mathbf{a} \mathrm{Al} / \mathrm{ZnO} / \mathrm{Ti}_{3} \mathrm{C}_{2} \mathrm{~T}_{\mathrm{x}}$ and $\mathbf{b} \mathrm{Al} / \mathrm{ZnO}: \mathrm{Pd} / \mathrm{Ti}_{3} \mathrm{C}_{2} \mathrm{~T}_{\mathrm{x}}$

white light is made to fall on one face of the fiber with the sensing probe at a suitable angle. The SPR curve recorded at the other end of the fiber gives ample information on the resonance wavelength, change of RI of sensing medium, and sensitivity of the sensor and accuracy of sensing. Usually, the Full-Width Half Maximum (FWHM) of the curve is considered for calculating the spectral width. Figure 2 illustrates two different SPR curves. Depending on parameters like the type and thickness of the different layers of the sensing probe and the RI of the analyte $\left(\mathrm{n}_{\mathrm{s}}\right)$, the SPR curve need not always be perfect like curve A, shown in Fig. 2. Calculation of FWHM is possible with the

Fig. 2 SPR curves- curve A is a typical SPR curve and curve B illustrates an SPR curve with variation depending on parameters like RI of the analyte and the nature and thickness of the layers of the sensor

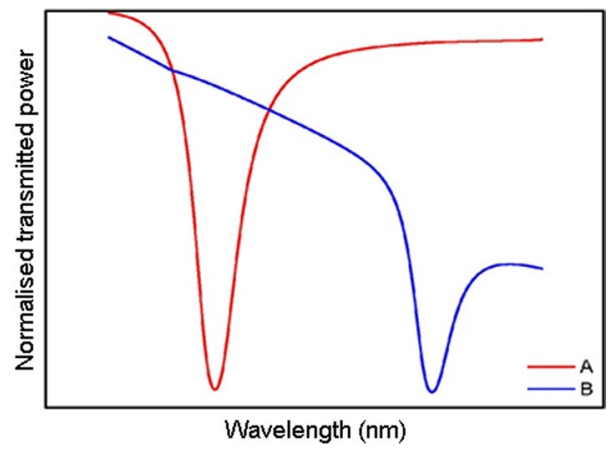


standard SPR curve A. Sometimes, the right-hand shoulder may fall much lower than the left one, as depicted by curve B in Fig. 2. The depth and sharpness of the SPR curve is critical as it affects the accuracy of determination of the resonant wavelength. The larger the spectral width, the lesser is the accuracy. Hence we have calculated the spectral width at a height corresponding to 0.1 unit above the tip of the SPR dip. For better clarity in representation and interpretation, the inverse of the spectral width is taken and is termed as detection accuracy (DA) (Sudheer et al. 2020). Use of DA facilitates easy analysis of the graphs and interpretation of the dependence of resonance wavelength on changes in RI.

The proposed SPR sensing probe is based on the Kretschmann configuration with the wavelength interrogation technique. Hence wavelength dependence of the dielectric constants of the core material of the optical fiber, aluminium, $\mathrm{ZnO}$, Palladium, and MXene need to be considered in the theoretical modeling. The dependence of the wavelength on the refractive index of the silica core of the PCS fiber is calculated as defined by the Sellmeier relation as (Ghatak and Thyagarajan 1998).

$$
n(\lambda)=\sqrt{1+\frac{A_{1} \lambda^{2}}{\lambda^{2}-B_{1}^{2}}+\frac{A_{2} \lambda^{2}}{\lambda^{2}-B_{2}^{2}}+\frac{A_{3} \lambda^{2}}{\lambda^{2}-B_{3}^{2}}}
$$

where $\lambda$ is the wavelength in $\mu \mathrm{m}$ and $A_{1}, A_{2}, A_{3}, B_{1}, B_{2}$ and $B_{3}$ are Sellmeier coefficients with values of $A_{1}=0.6961663, A_{2}=0.4079426, A_{3}=0.8974794, B_{1}=0.0684043, B_{2}=0.11$ 62414 and $B_{3}=9.896161$. The Drude dispersion model quantifies the wavelength dependence of the dielectric constant of the metals with the relation (Sharma and Gupta 2007; Sharma et al. 2007)

$$
\varepsilon_{m}(\lambda)=\varepsilon_{\mathrm{mr}}+i \varepsilon_{\mathrm{mi}}=1-\frac{\lambda^{2} \lambda_{c}}{\lambda_{p}^{2}\left(\lambda_{c}+i \lambda\right)}
$$

where $\lambda_{p}$ and $\lambda_{c}$ are respectively the plasma and collision wavelengths of the metal, $\varepsilon_{m r}$ and $\varepsilon_{m i}$ are respectively the real and imaginary parts of the dielectric constant of the metals and $\varepsilon_{\infty}$ correspond to the dielectric constant for the infinite value of the frequency. For metals, the value of $\varepsilon_{\infty}$ is 1 . The values of $\lambda_{p}$ and $\lambda_{c}$ for aluminium $\left(\mathrm{A}_{1}\right)$ are $1.0657 \times 10^{-7}$ and $2.4511 \times 10^{-5}$, respectively, where $\lambda$ is in meters (Ordal et al. 1983; Lambrecht and Reynaud 2000). Similarly, the dielectric constant of $\mathrm{ZnO}$ and $\mathrm{Pd}$ as a function of the wavelength of light is given as (Tabassum and Gupta 2015a, 2015b)

$$
\begin{gathered}
\varepsilon_{Z n O}(\lambda)=2.81418-\frac{0.87968 \lambda^{2}}{\left(\lambda^{2}-0.3042^{2}\right)-0.00711^{2}} \\
\varepsilon_{P d}(\lambda)=\left[-24.96364 e^{\left(\frac{-\lambda}{1.09383}\right)}+28.65615\right]+i\left[15.31843 e^{\left(\frac{\lambda}{0.76839}\right)}-16.97702\right]
\end{gathered}
$$

For the nanocomposite of $\mathrm{ZnO}$ and $\mathrm{Pd}$, particle size is considered to be much smaller than the wavelength of light. Nanoparticles of $\mathrm{Pd}$ is considered to be dispersed in the host solution of $\mathrm{ZnO}$ and is modeled with the Maxwell-Garnett model. The normalized transmitted power through the fiber measured at one end due to a white light source fed at the other end of the fiber in the SPR based sensor can be expressed as (Singh and Gupta 2010) 


$$
P_{\text {trans }}=\frac{\int_{\theta_{c r} / 2}^{\pi / 2} R_{P}^{N_{\text {ref }}(\theta)} \frac{n_{1}^{2} \sin \theta \cos \theta}{\left(1-n_{1}^{2} \cos ^{2} \theta\right)^{2}} d \theta}{\int_{\theta_{c r}}^{\pi / 2} \frac{n_{1}^{2} \sin \theta \cos \theta}{\left(1-n_{1}^{2} \cos ^{2} \theta\right)^{2}} d \theta}
$$

where $\mathrm{R}_{\mathrm{p}}$ is the net reflection coefficient of the ray incident at the core metal interface. $\theta_{\mathrm{cr}}$ is the critical angle of the fiber, $\mathrm{n}_{2}$ is the refractive index of the fiber cladding, $N_{\text {ref }}(\theta)$ represents the number of reflections the ray launched at an angle $\theta$ undergoes inside the fiber core. Also, $N_{\text {ref }}(\theta)=L / D \tan \theta$, where $L$ is the length of the sensing probe, and $D$ is the diameter of the fiber core.

In this work, the sensing probes considered are the multilayered structure, including the fiber core and the sensing medium. Hence, the N-layer matrix method (Hansen 1968) has been utilized to determine the value of $R_{p}$ accurately. Accordingly, the characteristic matrix for an $\mathrm{N}$-layer structure can be expressed as

$$
M=\prod_{k=2}^{N-1} M_{k}=\left[\begin{array}{ll}
M_{11} & M_{12} \\
M_{21} & M_{22}
\end{array}\right]=\left[\begin{array}{cc}
\cos \beta_{k} & \left(-i \sin \beta_{k}\right) / q_{k} \\
-i q_{k} \sin \beta_{k} & \cos \beta_{k}
\end{array}\right]
$$

where

$$
q_{k}=\left(\frac{\mu_{k}}{\varepsilon_{k}}\right)^{1 / 2} \cos \theta_{k}=\frac{\left(\varepsilon_{k}-n_{1}^{2} \sin ^{2} \theta_{1}\right)^{1 / 2}}{\varepsilon_{k}}
$$

and

$$
\beta_{k}=\frac{2 \pi}{\lambda} n_{k} \cos \theta_{k}\left(z_{k}-z_{k-1}\right)=\frac{2 \pi d_{k}}{\lambda}\left(\varepsilon_{k}-n_{1}^{2} \sin ^{2} \theta_{1}\right)^{1 / 2}
$$

The reflection coefficient $r_{p}$ of the incident wave through the $\mathrm{N}$ layered structure is given by

$$
r_{p}=\frac{\left(M_{11}+M_{12} q_{N}\right) q_{1}-\left(M_{21}+M_{22} q_{N}\right)}{\left(M_{11}+M_{12} q_{N}\right) q_{1}+\left(M_{21}+M_{22} q_{N}\right)}
$$

and the corresponding reflectance is $R_{p}=\left|r_{p}\right|^{2}$

The qualities of any SPR sensors are judged by three main parameters (Wu et al. 2018; Ghatak and Thyagarajan 1998).

(a) Sensitivity, $S=\frac{\text { change in resonant wavelenth }}{\text { change in refractive index }}=\frac{\Delta \lambda_{\text {res }}}{\Delta n_{s}}$

(b) The spectral width of the SPR curve.

(c) Range of refractive index values over which efficient sensing is possible.

Sensitivity is a major parameter that determines the quality of sensing. The more the shift in resonant wavelength for a unit change in $n_{s}$, the more accurate will be the sensing for the very small changes in $n_{s}$. In the same way, the spectral width of the SPR curve is also very important for an SPR sensor in that the accuracy of detection increases with smaller spectral width. Hence, a trade-off between the sensitivity and spectral width needs to be considered. 


\section{Results and discussion}

Certain benchmark values for the quality parameters (Sudheer et al. 2020; Sharma et al. 2007) are fixed by the authors to ensure better sensing - (i) $\lambda_{\text {res }}$ must lie in the visible region (ii) the sensitivity should not be less than $3000 \mathrm{~nm} / \mathrm{RIU}$ (iii) The DA should not be less than $0.015 \mathrm{~nm}^{-1}$. Simulation results on the $\lambda_{\text {res }}$, its spectral width, and depth of the SPR curve are collected for a change in RI of 0.0001 RIU.

\section{1 $\mathrm{Al} / \mathrm{ZnO} / \mathrm{Ti}_{3} \mathrm{C}_{2} \mathrm{Tx}$}

Figure 3a illustrates the variation of Sensitivity and DA for different thickness of the aluminium layer, with $10 \mathrm{~nm}$ of $\mathrm{ZnO}$ layer and a single layer of $\mathrm{Ti}_{3} \mathrm{C}_{2} \mathrm{~T}_{\mathrm{x}}$. No noticeable SPR curve is obtained for $10 \mathrm{~nm}$ thickness of aluminium. Up to $20 \mathrm{~nm}$ thickness of aluminium, the observed sensitivity is very low. After that, the sensitivity increases with an increase in the thickness of the aluminium layer up to $40 \mathrm{~nm}$. It remains at an almost saturation value of $\sim 10,600 \mathrm{~nm} / \mathrm{RIU}$ up to $50 \mathrm{~nm}$ and is observed to decrease with further increase in aluminium layer thickness (up to the considered thickness of $70 \mathrm{~nm}$ ). The DA is found to increase with an increase in the thickness of the Al layer. That is, even though aluminium layer thickness of $40 \mathrm{~nm}$ and $50 \mathrm{~nm}$ yielded almost the same sensitivity, the DA is better for $50 \mathrm{~nm}$ thickness. Figure $3 \mathrm{~b}$ depicts the normalized transmitted power corresponding to the different thickness of the aluminium layer as mentioned above. The resonant wavelength cannot be determined with the SPR curve corresponding to $20 \mathrm{~nm}$ thickness. The curve corresponding to $40 \mathrm{~nm}$ thickness exhibited larger red shifts and is of comparatively larger spectral width. For $50 \mathrm{~nm}$ thickness, the curve made only a lesser red shift, with a comparatively lesser spectral width and very good depth. The curves for $60 \mathrm{~nm}$ and above (not shown) exhibits very small depth.

Hence $50 \mathrm{~nm}$ is considered as the optimum thickness of aluminium in all the configurations. The variation of sensitivity with different layers of $\mathrm{Ti}_{3} \mathrm{C}_{2} \mathrm{~T}_{\mathrm{x}}$ for $50 \mathrm{~nm}$ of aluminium and $10 \mathrm{~nm}$ of a $\mathrm{ZnO}$ is plotted in Fig. 4a, which shows that a single layer of $\mathrm{Ti}_{3} \mathrm{C}_{2} \mathrm{~T}_{\mathrm{x}}$ yields higher sensitivity of $\sim 10,350 \mathrm{~nm} / \mathrm{RIU}$. The sensitivity is found to decrease for a further increase in the number of $\mathrm{Ti}_{3} \mathrm{C}_{2} \mathrm{~T}_{\mathrm{x}}$ layers. The DA increases with an increase in the number

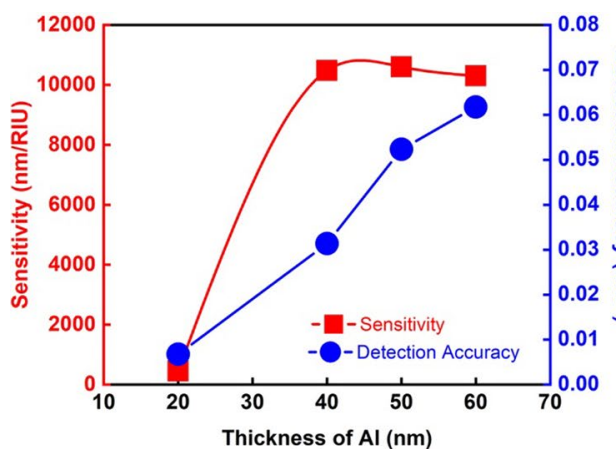

(a)

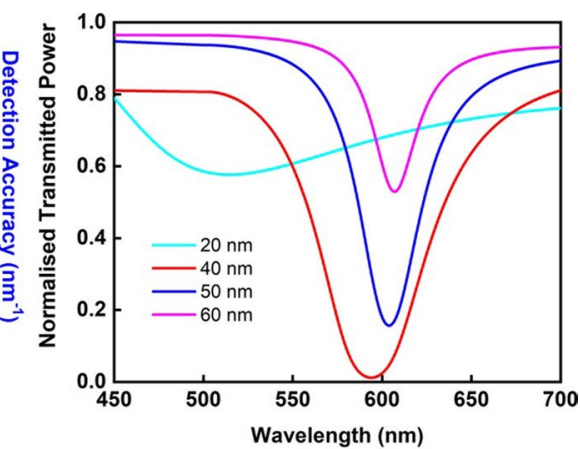

(b)

Fig. 3 a Variation of sensitivity and detection accuracy as a function of different thickness of Al measured at $\mathrm{n}_{\mathrm{s}}=1.413$ with a single layer of MXene and $10 \mathrm{~nm}$ of $\mathrm{ZnO}$. b Normalised transmitted power as a function of the wavelength for different thickness of Al measured at $n_{s}=1.413$ with a single layer of MXene and $10 \mathrm{~nm}$ of $\mathrm{ZnO}$ 


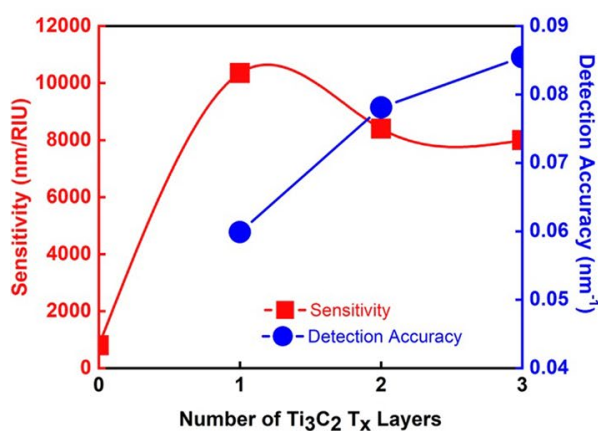

(a)

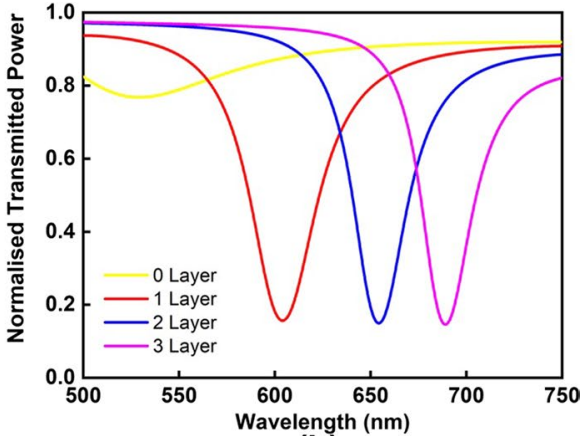

(b)

Fig. 4 a Variation of sensitivity and detection accuracy as a function of the number of layers of MXene, measured at $\mathrm{n}_{\mathrm{s}}=1.413$ with $50 \mathrm{~nm}$ of $\mathrm{Al}$ and $10 \mathrm{~nm}$ of $\mathrm{ZnO}$. b Wavelength dependence of the normalized transmitted power at $\mathrm{n}_{\mathrm{s}}=1.413$ for the different number of MXene layers, with $50 \mathrm{~nm}$ of $\mathrm{Al}$ and $10 \mathrm{~nm}$ of $\mathrm{ZnO}$

of $\mathrm{Ti}_{3} \mathrm{C}_{2} \mathrm{~T}_{\mathrm{x}}$ layers. Also, the $\lambda_{\text {res }}$ experienced a red shift with an increase in $\mathrm{Ti}_{3} \mathrm{C}_{2} \mathrm{~T}_{\mathrm{x}}$ layers. Variation in sensitivity and DA as a function of RI, corresponding to $5 \mathrm{~nm}$ and $10 \mathrm{~nm}$ thickness of $\mathrm{ZnO}, 50 \mathrm{~nm}$ of aluminium and a single layer of $\mathrm{Ti}_{3} \mathrm{C}_{2} \mathrm{~T}_{\mathrm{x}}$ are shown in Fig. $5 \mathrm{a}$.

With $5 \mathrm{~nm}$ of $\mathrm{ZnO}$, no noticeable SPR dip is observed for values of $n_{\mathrm{s}}<1.36$, whereas for $\mathrm{n}_{\mathrm{s}}=1.361$ to 1.375 , very low sensitivity is observed. The calculated sensitivity is well above the acceptable benchmark value for $n_{s}$ values from 1.38 to 1.416. Beyond $n_{s}=1.416$, the $\lambda_{\text {res }}$ is observed to shift to the IR region. The sensitivity is found to increase slightly up to $\mathrm{n}_{\mathrm{s}}=1.392$ and after that increases progressively with $\mathrm{n}_{\mathrm{s}}$. A sensitivity of $11,250 \mathrm{~nm} / \mathrm{RIU}$ is calculated for $\mathrm{n}_{\mathrm{s}}=1.416$. In fact, with $5 \mathrm{~nm}$ thickness of $\mathrm{ZnO}$, the effective sensing range is from $n_{s}=1.38$ to 1.416 . The DA is observed to decrease with an increase in $n_{s}$, but is within the acceptable benchmark value. Calculations with $10 \mathrm{~nm}$ thickness of $\mathrm{ZnO}$ observe no noticeable SPR dip up to $\mathrm{n}_{\mathrm{s}}$ values of 1.39 and thereafter minimal sensitivity value up to $\mathrm{n}_{\mathrm{s}}=1.39$. For $\mathrm{n}_{\mathrm{s}}=1.4$ to 1.42 steady increase in sensitivity with $\mathrm{n}_{\mathrm{s}}$ is observed. Sensitivity of $14,000 \mathrm{~nm} / \mathrm{RIU}$ is calculated for $\mathrm{n}_{\mathrm{s}}=1.419$. For $\mathrm{n}_{\mathrm{s}}$ greater than 1.42 , the $\lambda_{\text {res }}$ shifts to the IR region. The sensing range is minimal, ranging from $n_{s}=1.4$ to 1.42 . The observed SPR curves are so asymmetric that DA could be calculated only for a very narrow range of refractive index and hence not included in the graph. The calculated DA is in the acceptable range. A much higher sensitivity of $19,400 \mathrm{~nm} / \mathrm{RIU}$ is calculated for $\mathrm{n}_{\mathrm{s}}=1.422$ (not shown in the graph). The DA calculated is slightly higher. The sensing range is constricted to $\mathrm{n}_{\mathrm{s}}=1.419$ to 1.422 . Thus it is observed that an increase in the thickness of $\mathrm{ZnO}$ increases the sensitivity and the value of RI that can be sensed. But the lower range of sensing range got constricted largely.

The variation of sensitivity and DA with different thickness of $\mathrm{ZnO}, 50 \mathrm{~nm}$ of aluminium, a single layer of $\mathrm{Ti}_{3} \mathrm{C}_{2} \mathrm{~T}_{\mathrm{x}}$ and $\mathrm{n}_{\mathrm{s}}=1.412$ is shown in Fig. $5 \mathrm{~b}$. Up to around $4.5 \mathrm{~nm}$ thickness of $\mathrm{ZnO}$, no noticeable effect on the sensitivity enhancement is seen. Thereafter the sensitivity gradually increases and reaches a maximum value of $11,550 \mathrm{~nm} / \mathrm{RIU}$ at $11 \mathrm{~nm}$ thickness of $\mathrm{ZnO}$, and with further increase in $\mathrm{ZnO}$ thickness, shows a reduction in sensitivity. The DA decreases progressively but is within the acceptable range. The plot of the normalized transmitted power for different thicknesses of $\mathrm{ZnO}$ with $50 \mathrm{~nm}$ of aluminium, a single layer of $\mathrm{Ti}_{3} \mathrm{C}_{2} \mathrm{~T}_{\mathrm{x}}$, and $\mathrm{n}_{\mathrm{s}}=1.412$ depicted in Fig. $5 \mathrm{c}$ shows that all the SPR curves are of almost the same dip. But they experience a blue shift with an increase in $\mathrm{ZnO}$ 


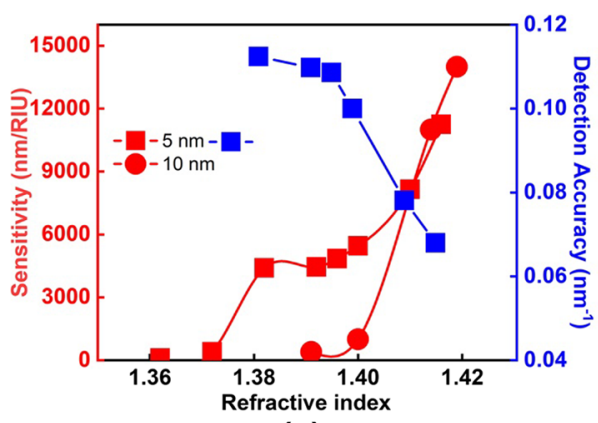

(a)

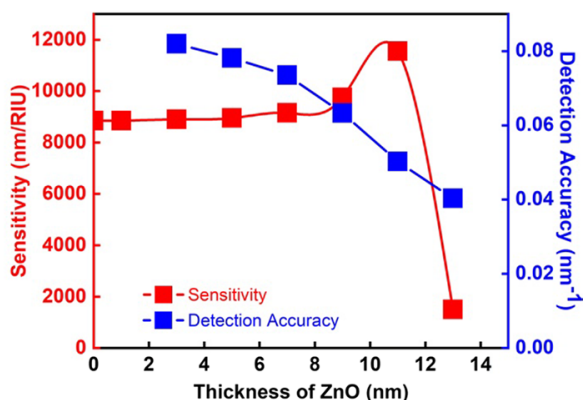

(b)

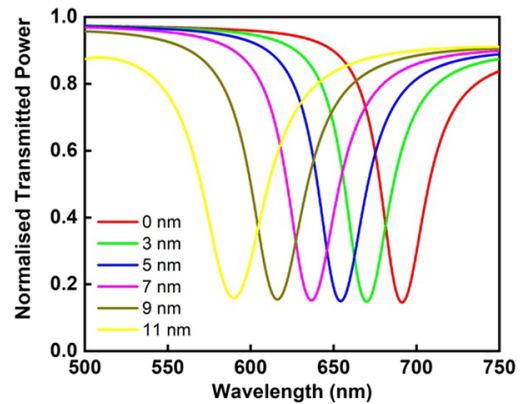

(c)

Fig. 5 a Variation of sensitivity and detection accuracy as a function of the refractive index of the analytes, with $50 \mathrm{~nm}$ of $\mathrm{Al}$ and a single layer of MXene for different thickness of $\mathrm{ZnO}$. b Variation of sensitivity and detection accuracy as a function of the thickness of $\mathrm{ZnO}$ measured at $\mathrm{n}_{\mathrm{s}}=1.413$ with $50 \mathrm{~nm}$ of $\mathrm{Al}$ and a single layer of Mxene. c Normalised transmitted power as a function of wavelength for different thickness of $\mathrm{ZnO}$ measured at $\mathrm{n}_{\mathrm{s}}=1.413$ with $50 \mathrm{~nm}$ of $\mathrm{Al}$ and a single layer of MXene

thickness. This configuration can lead to designing SPR biosensors and also sensors for gases and liquids of RI greater than 1.38.Thus $50 \mathrm{~nm}$ of aluminium, $11 \mathrm{~nm}$ of $\mathrm{ZnO}$, and a single layer of $\mathrm{Ti}_{3} \mathrm{C}_{2} \mathrm{~T}_{\mathrm{x}}$ will be the optimum values for efficient sensing.

\subsection{Al/ZnO: $\mathrm{Pd} / \mathrm{Ti}_{3} \mathrm{C}_{2} \mathrm{~T}_{x}$}

This is a three-layer configuration, just like the $\mathrm{Al} / \mathrm{ZnO} / \mathrm{Ti}_{3} \mathrm{C}_{2} \mathrm{~T}_{\mathrm{x}}$ sensing probe described above, where the $\mathrm{ZnO}$ sandwich layer is replaced by a nanocomposite of palladium dispersed in $\mathrm{ZnO}$. Here also the optimum thickness of aluminium is taken as $50 \mathrm{~nm}$ and of $\mathrm{Ti}_{3} \mathrm{C}_{2} \mathrm{~T}_{\mathrm{x}}$ as a single layer. Calculations have been done with different volume fractions (f) and thickness of the $\mathrm{ZnO}$ : $\mathrm{Pd}$ nanocomposite. The effect of incorporating the $\mathrm{ZnO}$ : $\mathrm{Pd}$ nanocomposite can be understood with the illustrative graphs in Fig. 6. Figure 6a illustrates the variations in sensitivity and detection accuracy of the sensing probe with $10 \mathrm{~nm}$ thick $\mathrm{ZnO}$ : Pd nanocomposite layer for $\mathrm{f}=0.2,0.4$ and 0.6 .

For $\mathrm{f}=0.2$, no SPR dip is observed for $\mathrm{n}_{\mathrm{s}}$ values less than or equal to 1.3. For $\mathrm{n}_{\mathrm{s}}=1.3$ to 1.35 , very low sensitivity is observed. Appreciable sensitivity is seen for $n_{s}$ values from 1.37 to 1.398 , beyond which the $\lambda_{\text {res }}$ shifted to the IR region. Maximum Sensitivity of $7250 \mathrm{~nm} / \mathrm{RIU}$ is calculated for $\mathrm{n}_{\mathrm{s}}=1.398$. Though the DA is observed to be lesser than that of $\mathrm{Al} / \mathrm{ZnO} / \mathrm{Ti}_{3} \mathrm{C}_{2} \mathrm{~T}_{\mathrm{x}}$ configuration, the values are well within the acceptable range. 


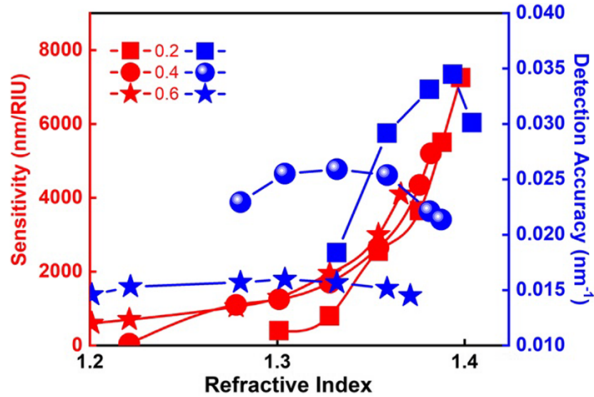

(a)

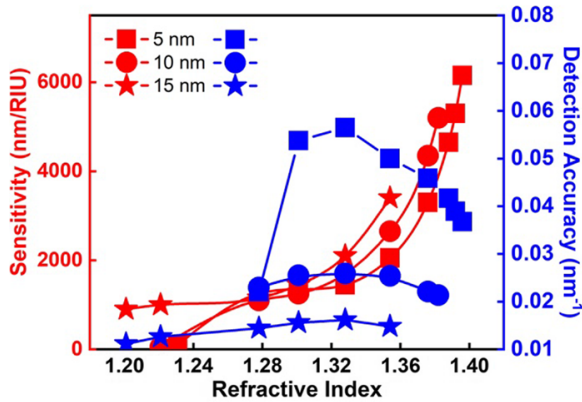

(c)

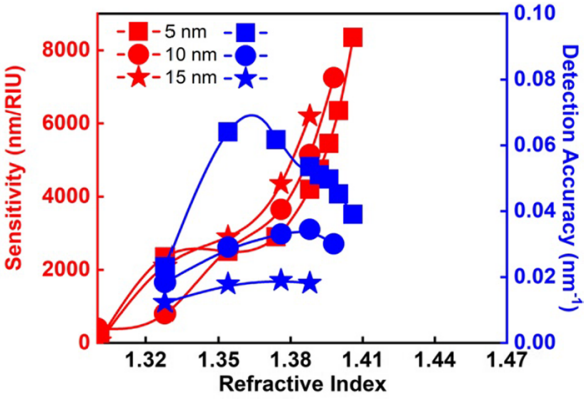

(b)

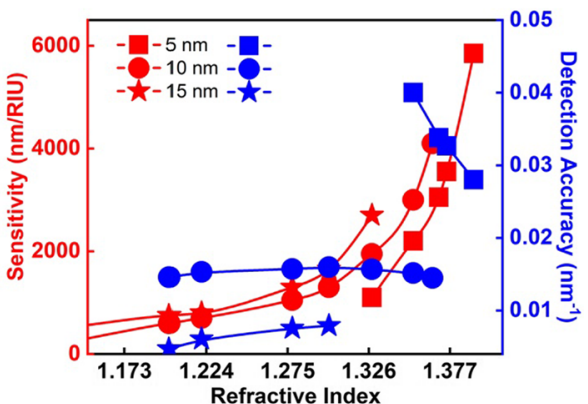

(d)

Fig. 6 Sensitivity and detection accuracy as a function of the refractive index of the analytes. a for the different volume fraction of $\mathrm{ZnO}$ : Pd with $50 \mathrm{~nm}$ of $\mathrm{Al}$, a single layer of MXene and $10 \mathrm{~nm}$ thickness of $\mathrm{ZnO}$ : $\mathrm{Pd}$ nanocomposite. $\mathbf{b}$ for different thickness of $\mathrm{ZnO}$ : $\mathrm{Pd}$ nanocomposite with $50 \mathrm{~nm}$ of $\mathrm{Al}$, a single layer of MXene and $\mathrm{f}=0.2$. $\mathbf{c}$ for different thickness of $\mathrm{ZnO}$ : Pd nanocomposite with $50 \mathrm{~nm}$ of $\mathrm{Al}$, a single layer of MXene and $\mathrm{f}=0.4 \mathbf{d}$ for different thickness of $\mathrm{ZnO}$ : $\mathrm{Pd}$ nanocomposite with $50 \mathrm{~nm}$ of $\mathrm{Al}$, a single layer of MXene and $\mathrm{f}=0.6$

With $\mathrm{f}=0.4$, SPR dip is observed only after $\mathrm{n}_{\mathrm{s}}=1.22$. An acceptable range of sensitivity is observed from $n_{s}=1.37$ to 1.382 . Beyond $n_{s}=1.382$ the $\lambda_{\text {res }}$ shifts to the IR region. Similarly, for $\mathrm{f}=0.6$, the simulation does not yield any SPR dip up to $\mathrm{n}_{\mathrm{s}}=1.109$. From $\mathrm{n}_{\mathrm{s}}=1.1$ to 1.35 , the observed sensitivity is very low. The acceptable range of sensitivity is calculated for $\mathrm{n}_{\mathrm{s}}=1.352$ to 1.366 , above which the $\lambda_{\text {res }}$ shifts to the IR region. Sensitivity of $4100 \mathrm{~nm} / \mathrm{RIU}$ is calculated for $\mathrm{n}_{\mathrm{s}}=1.366$. The DA observed is lower than that for $\mathrm{f}=0.4$. The calculated sensitivity is found to increase with the increase in the value of possible $n_{\mathrm{s}}$. For any value of $\mathrm{n}_{\mathrm{s}}$ in the possible range, the sensitivity is found to increase with an increase in volume fraction. Also, the lowering of the lower and upper limits of the sensing range can be noted. In all the cases, the $\lambda_{\text {res }}$ experience a redshift with an increase in the value of $n_{s}$. The SPR curves observed for $f=0.8$ is much wide that accurate detection of $\lambda_{\text {res }}$ will be difficult.

The analysis can be much clearer with the plots of Fig. 6b, c, and d, which depicts the variation of sensitivity and DA with $\mathrm{n}_{\mathrm{s}}$ for the selected thickness values of $\mathrm{ZnO}$ : $\mathrm{Pd}$ nanocomposite for different volume fractions of $0.2,0.4$ and 0.6 respectively. Figure $6 \mathrm{~b}$ illustrates the variations in sensitivity and DA with the nanocomposite thickness of $5 \mathrm{~nm}$, $10 \mathrm{~nm}$, and $15 \mathrm{~nm}$ for $\mathrm{f}=0.2$. With $5 \mathrm{~nm}$ thickness of the nanocomposite, effective sensing is possible only for values of $n_{s}=1.38$ to 1.406 . The maximum sensitivity of $8350 \mathrm{~nm} /$ RIU is calculated for $n_{s}=1.406$. With $10 \mathrm{~nm}$ thickness, the sensing range is from $n_{s}=1.37$ 
to 1.398 , with a maximum sensitivity of $7250 \mathrm{~nm} / \mathrm{RIU}$. For $15 \mathrm{~nm}$, the effective sensing range gets limited to $n_{s}=1.36$ to 1.388 with enhanced sensitivity. Sensitivity of $6200 \mathrm{~nm} /$ RIU is calculated for $n_{s}=1.388$. The DA is also observed to decrease with an increase in thickness of the nanocomposite. Figure $6 \mathrm{c}$ shows the variations in sensitivity and DA with $\mathrm{ZnO}$ : Pd thickness of $5 \mathrm{~nm}, 10 \mathrm{~nm}$ and $15 \mathrm{~nm}$ for $\mathrm{f}=0.4$. With $\mathrm{ZnO}$ : Pd thickness of $5 \mathrm{~nm}$, the sensing range extended from $\mathrm{n}_{\mathrm{s}}=1.373$ to 1.396 imparting $6150 \mathrm{~nm} / \mathrm{RIU}$ sensitivity for $\mathrm{n}_{\mathrm{s}}=1.396$. For $10 \mathrm{~nm}$ thickness, the sensing range is observed to be from $\mathrm{n}_{\mathrm{s}}=1.37$ to 1.382 with a sensitivity of $5200 \mathrm{~nm} / \mathrm{RIU}$ at $\mathrm{n}_{\mathrm{s}}=1.382$. Though SPR curve can be obtained for values of $\mathrm{n}_{\mathrm{s}}$ from 1.11 onwards, effective sensing can be had only for a very narrow span of $n_{s}=1.348$ to 1.354 , when the thickness of the nanocomposite is $15 \mathrm{~nm}$ and $\mathrm{f}=0.4$. A sensitivity of $3400 \mathrm{~nm} / \mathrm{RIU}$ is observed for $\mathrm{n}_{\mathrm{s}}=1.354$. The nanocomposite of $15 \mathrm{~nm}$ thickness yields higher sensitivity and lesser DA than that of $10 \mathrm{~nm}$. Figure $6 \mathrm{~d}$ depicts the variation of sensitivity and DA with $10 \mathrm{~nm}, 15 \mathrm{~nm}$ of the nanocomposite for $\mathrm{f}=0.6$. The sensing range from $\mathrm{n}_{\mathrm{s}}=1.37$ to 1.392 for a thickness of $5 \mathrm{~nm}$ imparting a sensitivity of $5850 \mathrm{~nm} / \mathrm{RIU}$ at $\mathrm{n}_{\mathrm{s}}=1.392$. With $10 \mathrm{~nm}$ thickness, an acceptable range of sensitivity is observed only for $\mathrm{n}_{\mathrm{s}}=1.352$ to 1.366 . With $15 \mathrm{~nm}$ of nanocomposite and volume fraction of 0.6 , though SPR curves are observed for $n_{s}=1.01$ to 1.328 , the sensitivity is not up to the acceptable benchmarked value. Figure 7a depicts the SPR curves corresponding to $\mathrm{ZnO}$ : Pd thickness of $5 \mathrm{~nm}, 10 \mathrm{~nm}$, and $15 \mathrm{~nm}$ for a volume fraction of 0.2 and $\mathrm{n}_{\mathrm{s}}=1.355$. Similarly, the SPR curves corresponding to volume fractions of $0.2,0.4$, and 0.6 for $\mathrm{ZnO}$ : Pd thickness of $10 \mathrm{~nm}$ and $n_{s}=1.355$ is illustrated in Fig. 7b. It is observed that with an increase in volume fraction and thickness of the nanocomposite, the SPR curves experience a decrease in depth and DA as well as redshift in $\lambda_{\text {res }}$. Thus in all the cases analyzed, with an increase in the thickness of the nanocomposite and also the volume fraction, for any value of RI, the $\lambda_{\text {res }}$ experience redshift, and the sensitivity is found to increase. The nanocomposite of $20 \mathrm{~nm}$ thickness does not provide acceptable values of sensitivity (not shown).

Both of the proposed sensor configurations are of the same number of layers (five layers, including the fiber core and the analyte). The consolidation of the performance analysis of both the configurations on different analytes, subject to the benchmark conditions

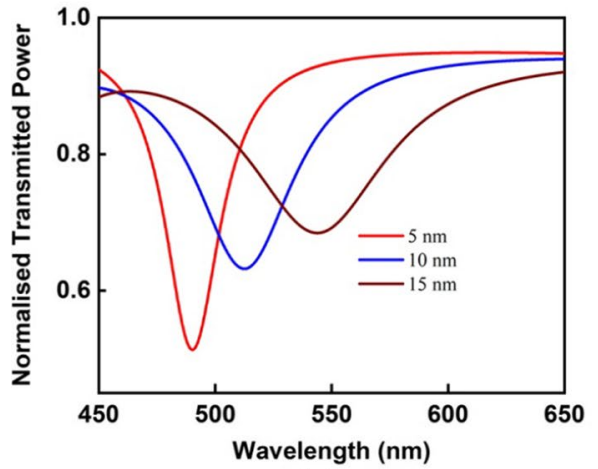

(a)

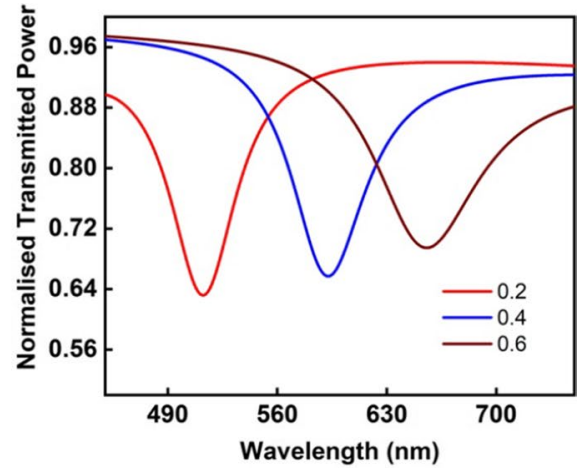

(b)

Fig. 7 Normalised transmitted power as a function of wavelength for the different, a thickness of $\mathrm{ZnO}$ : $\mathrm{Pd}$ nanocomposite at $\mathrm{f}=0.2$, with $50 \mathrm{~nm}$ of $\mathrm{Al}$, a single layer of $\mathrm{MXene}$ and $\mathrm{n}_{\mathrm{s}}=1.355$. b volume fraction of the nanocomposite, with $50 \mathrm{~nm}$ of $\mathrm{Al}$, a single layer of MXene, $10 \mathrm{~nm}$ of $\mathrm{ZnO}$ : Pd nanocomposite and $\mathrm{n}_{\mathrm{s}}=1.355$ 
of sensitivity ( $\geq 3000 \mathrm{~nm} / \mathrm{RIU}$ ), detection accuracy $\left(\geq 0.013 \mathrm{~nm}^{-1}\right.$ ), and spectral range of $\lambda_{\text {res }}$ (visible range) is furnished below in Table 1 . The table provides clear information on the possible sensing range and the valid sensitivity for each configuration. The sensor with $\mathrm{ZnO}$ as the sandwich layer finds application for analytes of RI 1.388-1.422. Similarly, the second configuration with $\mathrm{ZnO}$ : Pd nanocomposite can be made use of for RI values 1.354 to 1.406 . Though sensors with ZnO: Pd offers lesser Sensitivity and DA compared to that with $\mathrm{ZnO}$, they possess a broader sensing range of the analytes. These sensors can be made use of for biosensing different body fluids and also in sensing of VOCs like acetone and ethanol. The optimum thickness of aluminium is confirmed to be $50 \mathrm{~nm}$, and of $\mathrm{Ti}_{3} \mathrm{C}_{2} \mathrm{~T}_{\mathrm{x}}$ is a single layer. Therefore, the physical realization of the sensor can be done with proper selection of the configuration and thickness and volume fraction of the sandwich layer depending on the application and the required performance parameter values. But of course, since the calculations and consolidations in this work are based on theoretical modeling, slight changes may happen while dealing with the real cases.

\section{Conclusion}

In the present work, two different fiber optic SPR sensor configurations are proposed. Both the configurations utilize $\mathrm{Ti}_{3} \mathrm{C}_{2} \mathrm{~T}_{\mathrm{x}}$ as the outermost layer interacting with the analytes. The unique characteristics of $\mathrm{Ti}_{3} \mathrm{C}_{2} \mathrm{~T}_{\mathrm{x}}$ offer several advantages to find application in invasive and noninvasive biosensing of body fluids and VOCs. The $\mathrm{Al} / \mathrm{ZnO} /$ $\mathrm{Ti}_{3} \mathrm{C}_{2} \mathrm{~T}_{\mathrm{x}}$ configuration works effectively for $\mathrm{RI}$ values of $1.388-1.422$ and the $\mathrm{Al} / \mathrm{ZnO}$ : $\mathrm{Pd} / \mathrm{Ti}_{3} \mathrm{C}_{2} \mathrm{~T}_{\mathrm{x}}$ configuration with 1.354-1.406. Proper choice of the thickness and volume fractions of the sandwich layer will yield better biosensors. Since the calculations and consolidations in this work are based on theoretical modeling, the chances of slight

Table 1 Sensitivity of the sensor configurations for different thickness and volume fractions of $\mathrm{ZnO}$ and $\mathrm{ZnO}$ : Pd at different RI of analytes. Each column shows the minimum and maximum values of the acceptable sensitivities and the corresponding values of RI. Each row shows the acceptable sensitivity values of each configuration for different RI values

\begin{tabular}{|c|c|c|c|c|c|c|c|c|c|c|c|c|}
\hline \multirow[t]{3}{*}{ RI } & \multirow[t]{3}{*}{$\mathrm{ZnO}(5 \mathrm{~nm})$} & \multirow[t]{3}{*}{$\mathrm{ZnO}(10 \mathrm{~nm})$} & \multirow[t]{3}{*}{$\mathrm{ZnO}(15 \mathrm{~nm})$} & \multicolumn{3}{|c|}{$\mathrm{ZnO}: \mathrm{Pd}(5 \mathrm{~nm})$} & \multicolumn{3}{|c|}{$\mathrm{ZnO}: \mathrm{Pd}(10 \mathrm{~nm})$} & \multicolumn{3}{|c|}{$\begin{array}{l}\mathrm{ZnO}: \mathrm{Pd} \\
(15 \mathrm{~nm})\end{array}$} \\
\hline & & & & \multicolumn{9}{|l|}{$\mathrm{f}$} \\
\hline & & & & 0.2 & 0.4 & 0.6 & 0.2 & 0.4 & 0.6 & 0.2 & 0.4 & 0.6 \\
\hline 1.354 & - & - & - & - & - & - & - & - & 3 & - & 3.4 & - \\
\hline 1.364 & - & - & - & - & - & - & - & - & 4.1 & - & - & - \\
\hline 1.376 & - & - & - & 3 & 3.3 & 3.55 & 3.65 & 4.35 & - & 4.35 & - & - \\
\hline 1.388 & 4.41 & - & - & 4.2 & 4.65 & 5.1 & 5.15 & - & - & 6.2 & - & - \\
\hline 1.396 & 4.85 & - & - & 5.45 & 6.16 & -7.25 & - & - & - & - & - & - \\
\hline 1.400 & 5.45 & - & - & 6.35 & - & - & - & - & - & - & - & - \\
\hline 1.406 & - & - & - & 8.35 & - & - & - & - & - & - & - & - \\
\hline 1.41 & 10 & 11 & - & - & - & - & - & - & - & - & - & - \\
\hline 1.416 & 11.25 & 11.95 & - & - & - & - & - & - & - & - & - & - \\
\hline 1.41 & - & 14 & - & - & - & - & - & - & - & - & - & - \\
\hline 1.42 & - & - & 19.4 & - & - & - & - & - & - & - & - & - \\
\hline
\end{tabular}


deviation from the calculated values cannot be neglected while dealing with the physical implementation of the sensor. The proposed biosensor can be an excellent tool for COVID-19 detection as the refractive index of mucus and serum falls in this range, which is to be explored using real samples.

Author contributions All authors contributed equally to the manuscript.

\section{Declarations}

Conflict of interest The authors declare that they have no competing interest.

\section{References}

Abd Rahim, A.F., Hashim, M.R., Ali, N.K.: High sensitivity of palladium on porous silicon MSM photodetector. Phys. B Condens. Matter. 406, 1034-1037 (2011). https://doi.org/10.1016/j.physb.2010.12.056

Andre, R.S., Sanfelice, R.C., Pavinatto, A., Mattoso, L.H.C., Correa, D.S.: Hybrid nanomaterials designed for volatile organic compounds sensors: a review. Mater. Des. 156, 154-166 (2018). https://doi.org/10.1016/j. matdes.2018.06.041

Beck, U., Hertwig, A., Kormunda, M., Krause, A., Krüger, H., Lohse, V., Nooke, A., Pavlik, J., Steinbach, J.: SPR enhanced ellipsometric gas monitoring on thin iron doped tin oxide layers. Sens. Actuators B Chem. 160, 609-615 (2011). https://doi.org/10.1016/j.snb.2011.08.036

Galassetti, P.R., Novak, B., Nemet, D., Rose-Gottron, C., Cooper, D.M., Meinardi, S., Newcomb, R., Zaldivar, F., Blake, D.R.: Breath ethanol and acetone as indicators of serum glucose levels: an initial report. Diabetes Technol. Ther. 7, 115-123 (2005). https://doi.org/10.1089/dia.2005.7.115

Ghatak, A., Thyagarajan, K.: An introduction to fiber optics. Cambridge University Press, Cambridge (1998)

Ghosh, N., Gupta, G., Boopathi, M., Pal, V., Singh, A.K., Gopalan, N., Goel, A.K.: Surface plasmon resonance biosensor for detection of Bacillus anthracis, the causative agent of anthrax from soil samples targeting protective antigen. Indian J. Microbiol. 53, 48-55 (2013). https://doi.org/10.1007/s12088-012-0334-3

Gruber, B., Keller, S., Groeger, T., Matuschek, G., Szymczak, W., Zimmermann, R.: Breath gas monitoring during a glucose challenge by a combined PTR-QMS/GC $\times$ GC-TOFMS approach for the verification of potential volatile biomarkers. J. Breath Res. 10, 036003 (2016). https://doi.org/10.1088/1752-7155/10/3/ 036003

Hamed, A.M.: Image processing of corona virus using interferometry. Opt. Photon. J. 06, 75-86 (2016). https:// doi.org/10.4236/opj.2016.65011

Hansen, W.N.: Electric fields produced by the propagation of plane coherent electromagnetic radiation in a stratified medium. J. Opt. Soc. Am. 58, 380 (1968). https://doi.org/10.1364/JOSA.58.000380

Homola, J.: On the sensitivity of surface plasmon resonance sensors with spectral interrogation. Sens. Actuators B Chem. 41, 207-211 (1997). https://doi.org/10.1016/S0925-4005(97)80297-3

Huang, J.C., Chang, Y.-F., Chen, K.-H., Su, L.-C., Lee, C.-W., Chen, C.-C., Chen, Y.-M.A., Chou, C.: Detection of severe acute respiratory syndrome (SARS) coronavirus nucleocapsid protein in human serum using a localized surface plasmon coupled fluorescence fiber-optic biosensor. Biosens. Bioelectron. 25, 320-325 (2009). https://doi.org/10.1016/j.bios.2009.07.012

Jorgenson, R.C., Yee, S.S.: A fiber-optic chemical sensor based on surface plasmon resonance. Sens. Actuators B Chem. 12, 213-220 (1993). https://doi.org/10.1016/0925-4005(93)80021-3

Lambrecht, A., Reynaud, S.: Casimir force between metallic mirrors. Eur. Phys. J. D - At. Mol. Opt. Phys. 8, 309-318 (2000). https://doi.org/10.1007/s100530050041

Li, J.P., Tredgold, R.H., Jones, R., Hodge, P.: Interactions of nitrogen dioxide with langmuir-Blodgett films of a copper porphyrin. Thin Solid Films 186, 167-176 (1990). https://doi.org/10.1016/0040-6090(90)90510-K

Liu, S., Deng, Z., Li, J., Wang, J., Huang, N.: Measurement of the refractive index of whole blood and its components for a continuous spectral region. J. Biomed. Opt. 24, 1 (2019). https://doi.org/10.1117/1.JBO.24.3. 035003

Nardi-Agmon, I., Peled, N.: Exhaled breath analysis for the early detection of lung cancer: recent developments and future prospects. Lung Cancer Targets Ther. 8, 31-38 (2017). https://doi.org/10.2147/LCTT.S104205

Ordal, M.A., Long, L.L., Bell, R.J., Bell, S.E., Bell, R.R., Alexander, R.W., Ward, C.A.: Optical properties of the metals $\mathrm{Al} \mathrm{Co}, \mathrm{Cu}, \mathrm{Au}, \mathrm{Fe}, \mathrm{Pb}, \mathrm{Ni}, \mathrm{Pd}, \mathrm{Pt}, \mathrm{Ag}, \mathrm{Ti}$, and $\mathrm{W}$ in the infrared and far infrared. Appl. Opt. 22, 1099 (1983). https://doi.org/10.1364/AO.22.001099 
Özgür, Ü., Alivov, Y.I., Liu, C., Teke, A., Reshchikov, M.A., Doğan, S., Avrutin, V., Cho, S.-J., Morkoç, H.: A comprehensive review of $\mathrm{ZnO}$ materials and devices. J. Appl. Phys. 98, 041301 (2005). https://doi.org/10. 1063/1.1992666

Pang, Y., Song, H., Cheng, W.: Using optical trap to measure the refractive index of a single animal virus in culture fluid with high precision. Biomed. Opt. Express. 7, 1672 (2016). https://doi.org/10.1364/BOE.7. 001672

Rakhi, R.B., Nayak, P., Xia, C., Alshareef, H.N.: Novel amperometric glucose biosensor based on MXene nanocomposite. Sci. Rep. 6, 36422 (2016). https://doi.org/10.1038/srep36422

Ruzsányi, V., Péter Kalapos, M.: Breath acetone as a potential marker in clinical practice. J. Breath Res. 11, 2400 (2017). https://doi.org/10.1088/1752-7163/aa66d3

Sharma, A.K., Gupta, B.D.: On the performance of different bimetallic combinations in surface plasmon resonance based fiber optic sensors. J. Appl. Phys. 101, 093111 (2007). https://doi.org/10.1063/1.2721779

Sharma, A.K., Jha, R., Gupta, B.D.: Fiber-optic sensors based on surface plasmon resonance: a comprehensive review. IEEE Sens. J. 7, 1118-1129 (2007). https://doi.org/10.1109/JSEN.2007.897946

Shukla, S., Sharma, N.K., Sajal, V.: Sensitivity enhancement of a surface plasmon resonance based fiber optic sensor using $\mathrm{ZnO}$ thin film: a theoretical study. Sens. Actuators B Chem. 206, 463-470 (2015). https://doi. org/10.1016/j.snb.2014.09.083

Singh, S., Gupta, B.D.: Simulation of a surface plasmon resonance-based fiber-optic sensor for gas sensing in visible range using films of nanocomposites. Meas. Sci. Technol. 21, 115202 (2010). https://doi.org/10. 1088/0957-0233/21/11/115202

Sinha, A., Zhao, D.H., Huang, Y., Lu, X., Chen, J., Jain, R.: MXene: An emerging material for sensing and biosensing. TrAC Trends Anal. Chem. 105(2018), 424-435 (2018). https://doi.org/10.1016/j.trac.2018.05. 021

Sudheer, V.R., Kumar, S.R.S., Sankararaman, S.: ultrahigh sensitivity surface plasmon resonance-based fiberoptic sensors using metal-graphene layers with Ti3C2Tx MXene overlayers. Plasmonics 15, 457-466 (2020). https://doi.org/10.1007/s11468-019-01035-3

Tabassum, R., Gupta, B.D.: Fiber optic manganese ions sensor using SPR and nanocomposite of ZnO-polypyrrole. Sens. Actuators B Chem. 220, 903-909 (2015a). https://doi.org/10.1016/j.snb.2015.06.018

Tabassum, R., Gupta, B.D.: Surface plasmon resonance-based fiber-optic hydrogen gas sensor utilizing palladium supported zinc oxide multilayers and their nanocomposite. Appl. Opt. 54, 1032 (2015b). https://doi. org/10.1364/AO.54.001032

Tredgold, R.H., Young, M.C.J., Hodge, P., Hoorfar, A.: Gas sensors made from Langmuir-Blodgett films of porphyrins. IEE Proc. I Solid State Electron Devices. 132, 151 (1985). https://doi.org/10.1049/ip-i-1.1985. 0031

Villuendas, F., Pelayo, J.: Optical fibre device for chemical seming based on surface plasmon excitridon. Sens. Actuators A Phys. 23, 1142-1145 (1990). https://doi.org/10.1016/0924-4247(90)87104-Q

Wang, F., Yang, C., Duan, C., Xiao, D., Tang, Y., Zhu, J.: An organ-like titanium carbide material (MXene) with multilayer structure encapsulating hemoglobin for a mediator-free biosensor. J. Electrochem. Soc. 162, B16-B21 (2015a). https://doi.org/10.1149/2.0371501jes

Wang, F., Yang, C., Duan, M., Tang, Y., Zhu, J.: TiO2 nanoparticle modified organ-like Ti3C2 MXene nanocomposite encapsulating hemoglobin for a mediator-free biosensor with excellent performances. Biosens. Bioelectron. 74, 1022-1028 (2015b). https://doi.org/10.1016/j.bios.2015.08.004

Wu, L., You, Q., Shan, Y., Gan, S., Zhao, Y., Dai, X., Xiang, Y.: Few-layer Ti3C2Tx MXene: a promising surface plasmon resonance biosensing material to enhance the sensitivity. Sens. Actuators B Chem. 277, 210-215 (2018). https://doi.org/10.1016/j.snb.2018.08.154

Zhu, J., Ha, E., Zhao, G., Zhou, Y., Huang, D., Yue, G., Hu, L., Sun, N., Wang, Y., Lee, L.Y.S., Xu, C., Wong, K.-Y., Astruc, D., Zhao, P.: Recent advance in MXenes: a promising 2D material for catalysis, sensor and chemical adsorption. Coord. Chem. Rev. 352, 306-327 (2017). https://doi.org/10.1016/j.ccr.2017.09.012

Publisher's Note Springer Nature remains neutral with regard to jurisdictional claims in published maps and institutional affiliations. 